\title{
How Do Metalogical Concepts Emerge?
}

\author{
Jerzy Pogonowski \\ Institute of Linguistics, Adam Mickiewicz University \\ ul. Międzychodzka 5, 60-371 Poznań, POLAND
}

$\underline{\text { pogoneamu.edu.pl }}$

We are going to share with the audience a few reflections about the origin (emergence) and development of some metalogical concepts, first of all those of categoricity and completeness. ${ }^{1}$

The idea of an unique description of some fundamental structures from arithmetics and geometry can be found in the works of the American Postulate Theorists (e.g. Veblen, Huntington) as well as in the pioneering works of Dedekind, Peano and Hilbert. The concepts of categoricity and completeness were intertwined at the very beginning; this situation culminated in the Gabelbarkeitssatz proposed by Carnap in 1928.

The problem of completeness (of a system of logic) was in the meantime approached and solved [Bernays 1918], [Post 1920, 1921], [Hilbert and Ackermann 1928], [Gödel 1930]. Non-completeness of most important deductive theories has been established [Gödel 1931], thus showing the limitations of the Hilbert's Program. First-order logic became a standard. Tarski has codified the foundations of metalogic; in particular, connections of (several versions of) categoricity and completeness with other concepts (e.g. that of a logical constant) have been clarified. The importance of the compactness property became evident.

Some fifty years ago one could observe a revival of logical systems stronger than first-order logic. As a later consequence of this, discussions about which logic is the logic became of new interest (e.g. the first-order thesis). Again, the concepts of categoricity and completeness play a central role there.

\section{References}

Awodey, S., Reck, E.H. 2002a. Completeness and Categoricity, Part I: Nineteenth-century Axiomatics to Twentiethcentury Metalogic. History and Philosophy of Logic 23, 1-30.

Awodey, S., Reck, E.H. 2002b. Completeness and Categoricity, Part II: Twentieth-Century Metalogic to Twenty-firstCentury Semantics. History and Philosophy of Logic 23, 77-94.

Bernays, P. 1918. Beiträge zur axiomatischen Behandlung des Logik-Kalküls. Habilitationsschrift, Universität Göttingen, [unpublished].

Corcoran, J. 1980. Categoricity. History and Philosophy of Logic 1, 187-207.

Dawson, J.W., Jr. 1993. The Compactness of First-Order Logic: From Gödel to Lindström. History and Philosophy of Logic 14, 15-38.

\footnotetext{
${ }^{1}$ This is an abstract of the talk given at Von Neumann's Birth Centenary Conference. Computational POWER FOR SOCIAL RESEARCH, Zakopane 2003. Institute of Linguistics, AMU, did not support my participation in this conference. I warmly thank Professor Witold Marciszewski for the invitation and for sponsoring my participation in the conference. The work on this abstract was also sponsored by the research project KBN 2H01A 00725 Metody nieskonczonościowe $w$ teorii definicji (Infinitary methods in the theory of definitions) headed by Professor Janusz Czelakowski at the Institute of Mathematics and Information Science, University of Opole, Poland. Last but not least, I warmly thank Alexander von Humboldt-Stiftung and Fachbereich Philosophie der Universität Konstanz, Germany, for providing me with excellent conditions for my research work in Konstanz during the Spring of 2003 - the present abstract is one of the results of that work.
} 
Gödel, K. 1930. Die Vollständigkeit der Axiome des logischen Funktionenkalküls. Monatshefte für Mathematik und Physik 37, 349-360.

Gödel, K. 1931. Über formal unentscheidbare Sätze der Principia Mathematica und verwandter Systeme. Monatshefte für Mathematik und Physik 38, 173-198.

Hilbert, D., Ackermann, W. 1928. Grundzüge der theoretischen Logik. Verlag von Julius Springer, Berlin.

Post, E. 1920. Determination of all closed systems of truth tables. Bulletin of American Mathematical Society XXVI, 437. Post, E. 1921. Introduction to a general theory of elementary propositions. American Journal of Mathematics XLIII, $163-185$

Read, S. 1997. Completeness and Categoricity: Frege, Gödel and Model Theory. History and Philosophy of Logic 18, 79-94.

Surma, S. (Ed.) 1973. Studies in the History of Mathematical Logic. Ossolineum.

Tennant, N. 2000. Deductive versus Expressive Power: a Pre-Gödelian Predicament. The Journal of Philosophy vol. XCVII, No. 5, 257-277. 